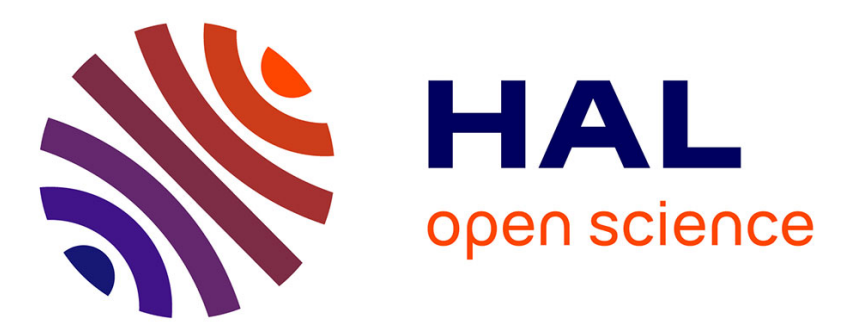

\title{
Modelling dynamic value streams in support of process design and evaluation
}

\author{
Richard Henry Weston, Kwabena Agyapong-Kodua, Joseph Ajaefobi
}

\section{To cite this version:}

Richard Henry Weston, Kwabena Agyapong-Kodua, Joseph Ajaefobi. Modelling dynamic value streams in support of process design and evaluation. International Journal of Computer Integrated Manufacturing, 2009, 22 (05), pp.411-427. 10.1080/09511920802527574 . hal-00513410

\section{HAL Id: hal-00513410 https://hal.science/hal-00513410}

Submitted on 1 Sep 2010

HAL is a multi-disciplinary open access archive for the deposit and dissemination of scientific research documents, whether they are published or not. The documents may come from teaching and research institutions in France or abroad, or from public or private research centers.
L'archive ouverte pluridisciplinaire HAL, est destinée au dépôt et à la diffusion de documents scientifiques de niveau recherche, publiés ou non, émanant des établissements d'enseignement et de recherche français ou étrangers, des laboratoires publics ou privés. 


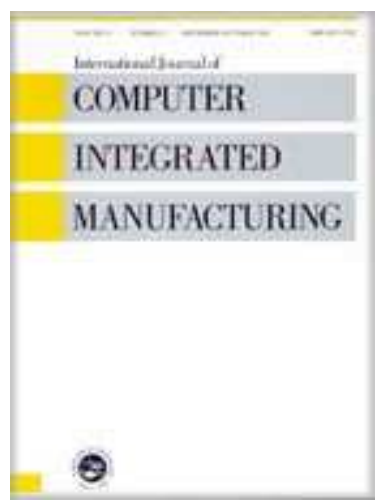

\section{Modelling dynamic value streams in support of process design and evaluation}

\begin{tabular}{|r|l|}
\hline Journal: & International Journal of Computer Integrated Manufacturing \\
\hline Manuscript ID: & TCIM-2007-IJCIM-0081.R2 \\
\hline Manuscript Type: & Original Manuscript \\
\hline Author: & 18-Aug-2008 \\
\hline Complete List of Authors: & $\begin{array}{l}\text { Weston, Richard; Loughborough University, Wolfson School of Mech } \\
\text { \& Man Eng'g } \\
\text { Agyapong-Kodua, Kwabena; Loughborough University, Mechanical } \\
\text { \& Manufacturing Engineering } \\
\text { Ajaefobi, Joseph; Loughborough University, Mechanical \& } \\
\text { Manufacturing Engineering }\end{array}$ \\
\hline Keywords: & ENTERPRISE MODELING, SIMULATION \\
\hline Keywords (user): & VALUE STREAM MODELLING, LEAN MANUFACTURING \\
\hline &
\end{tabular}

\section{S ScholarONE \\ Manuscript Central}


Modelling dynamic value streams in support of process design and evaluation

K A-Kodua, J O Ajaefobi and R H Weston

(k.a.kodua@lboro.ac.uk,j.o.ajaefobi@lboro.ac.uk,r.h.weston@lboro.ac.uk)

MSI Research Institute, Loughborough University, Loughborough, Leics., UK; Tel: 01509227501

\begin{abstract}
To remain competitive, most Manufacturing Enterprises (MEs) need cost effective and responsive business processes with capability to realise multiple value streams specified by changes in customer needs. Models of MEs can play a critical role in enabling enhanced enterprise process and systems design and change based on analysis of their performance, and ongoing management and control of their operation. Typical models of MEs can provide reusable computational representations of organisational structures, processes, information, resources and related value flows in an enterprise.
\end{abstract}

This paper presents a dynamic modelling approach to value stream mapping which enhances current best practice when reasoning about changing process and resource systems requirements. Here, coherent use of enterprise and simulation modelling techniques were deployed to develop value streams of a case study enterprise which is a make-to-order furniture manufacturing SME.

The paper will explain how models created during the modelling stages were validated and reused as a basis for informed SME decision making in relation to product realisation strategies and related organisation design and change decisions and actions.

Key words: Value stream modelling, Enterprise Modelling (EM), Simulation Modelling, Lean Manufacturing, Small and Medium-sized Enterprises (SMES)

Deleted:
Deleted: (SM)

\title{
1. Introduction
}

Notions about value stream mapping have an origin which has been attributed to the Toyota production system and its related Lean Manufacturing principles (Womack et al. 1990) Value stream mapping can help identify wasteful activities related to process segments, by analysing those activities or actions needed to produce Deleted: (Womack, Jones et al. 1990) products specified by customers. It follows that value stream mapping can provide an important 'tool' for reasoning about the design or re-design of processes. Lean thinkers, for over two decades, have claimed that through value stream mapping, 
most mass production systems can be transformed to lean production systems, (Hines and Nick 1997; Womack and Jones 2003). Further claims include the delivery of products in time; at a lower cost, of high quality and on continuous basis (Lee 2005) In principle value stream analysis can help specify processes with: integrated

Field Code Changed
Deleted: (Lee 2005)
single piece flow; defect prevention; production pull; continuous waste reduction; flexible team based work and active involvement and close integration with suppliers (Bicheno 2000). In practice, value stream maps are known to help identify (and therefore help eliminate or at least reduce) the wasteful activities that customers would not wish to pay for, hence making it a useful tool for process improvement.

It follows that value stream mapping has proven effective in many manufacturing organizations. However a critical consideration in this paper is to better understand whether value stream mapping can be an effective process redesign and improvement tool for manufacturing systems that need to realise multi-product flows. Unlike single flow manufacturing systems, many MEs are characterised by complex systems of processes with associated underpinning technical and resource systems which need to be properly coordinated to allow a variety of products to be realised through them over a varying period of time. Appropriate management of related changes is a key determinant for the MEs sustainability in a dynamic global market; because it may gain competitive advantage through achieving economies of scope as well as economies of scale (Vernadat 1996). Unfortunately, best industry practice current approaches to value stream mapping do not encode time dependencies related to product flows, controls, process instants and time dependent causal effects. This implies that an analysis of alternative flows of product (volume and mixes) through a shared process cannot accurately be modelled by current generation value stream maps to mimic real time instances in a ME. Hence current forms of value stream map cannot adequately enable organization strategies to be designed for future changes due to the complex and dynamic inputs inherent in MEs.

Another key challenge in real world manufacturing enterprises is that, systems are interconnected such that flows can be hard to 'see' when products have a multitude of options, with variations in lead times and cycle times, and processed through repetitive and multiple processes or cycles (Duggan 2002) Further process complexity arises where there are significant product mixes, shared resources with unsteady changes in information or material flow as well as control. In such 
circumstance, it becomes fairly difficult to identify product families and map their operational processes.

With the introduction of Computer-Integrated Manufacturing and the use of modern Information Technologies (IT), in principle manufacturing enterprises are able to achieve increased levels of flexibility in terms of organization, operations, product design and manufacturing. Also in principle, flexibility can be increased by adopting quick responsive modelling techniques to identify the values and cost which are being shared across a given process. This can obviously not be achieved by static mapping techniques.

An alternative to the mapping approach is to view all types of processes as multi perspective flows associated with ordered sets of activities. Such a technique can in part be provided by enterprise engineering and its associated modelling formalisms, (Ferreira and Mendonca 1994; Mertins and Jochem 1996; Bernus and Nemes 1996a) Inherently EM techniques separate models of problems from models of solutions and thus can provide significant benefit when designing and changing ME

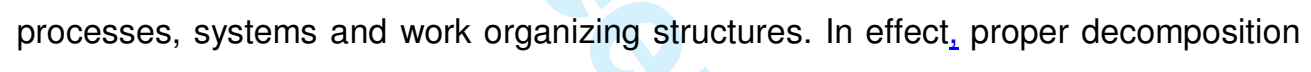
of enterprise requirements ensures that complex problems can be characterised and modelled in a modular form, so that analysis and understanding becomes easier. To predict the effect of changes impacting on enterprise models, it can be highly beneficial to link these models to simulation models with capabilities to replicate existing and predict future manufacturing enterprise behaviours (Carrie 1988; Askin 1993; Mendonca et al. 1993; Mertins et al. 2000),

Field Code Changed

Deleted: (Carrie 1988; Askin 1993)

A number of public domain Enterprise modelling_(EM) architectures, methodologies and techniques have been conceived to facilitate key aspects of process oriented organisational design and change. Currently there are many independently developed techniques for designing and implementing phases of an organization. One of the most important results derived from the ESPRIT projects has been the Computer Integrated Manufacturing Open System Architecture, its supporting modelling tools and validation in industrial environments (AMICE 1993; CEN/ISO 19440). Other key researchers have demonstrated how the application of CIMOSA methodologies and framework can help capture salient process oriented elements in organizations (Lutherer et al. 1994; Kosanke 1995; Zelm et al. 1995; Chatha and 
Weston 2005). Many other enterprise modelling architectures are currently in use. This includes Purdue Enterprise Reference Architecture which was published by Williams (Williams 1992), to provide a generic enterprise model reflecting the full life

Deleted: (PERA)

Field Code Changed cycle of enterprises. It is claimed that PERA uniquely provides a formal way to identify optimum levels of automation and addresses continuous processes and discrete parts manufacturing (Williams and Li 1998) Some known enterprise modelling tools are Architecture for Integrated Information Systems (Scheer 1992; Scheer 1994): Generic Enterprise Reference Architecture and methodology (Bernus and Nemes 1996b) and GRAI-GIM, a framework and modelling tool developed by the University of Bordeaux (Doumeingts et al. 1992).

Generally ${ }_{2}$ enterprise modelling techniques provide graphical modelling constructs to explicitly describe multi-perspective models of complex organisations that can be reused in support of decision making by relevant change actors. With such a purpose in mind, this paper sets out to explain how the use of state of the art Computer Integrated Manufacturing Open System Architecture, CIMOSA has enabled decomposition of various process segments of a make-to-order furniture manufacturing SME, in order to generate multi-perspective models of value streams. Use of this modelling approach was further enriched by the complementary use of causal loop dynamic modelling technique which enabled manufacturing process dynamics to be analysed. To facilitate process design and ME change specifications, the created static value stream models were subsequently transformed into dynamic simulation models that can be used to analyse and predict impacts of manufacturing process dynamics on value generation, when alternative process inputs were applied.

\section{BACKGROUND}

\subsection{Process design in MEs and related change problems}

Through the lifetime of MEs, small and large scale 'process design and change' are necessary to maintain competitive and timely organisational responses that satisfy customer and stakeholder needs and environmental constraints. This requires understandings about and manipulation of complex causal and temporal dependencies between changes made to 'strategic intentions'; 'business models'; 'product (and service) portfolios'; process configurations'; departmental boundaries and people reporting structures'; manufacturing policies'; 'work-organising methods';
Deleted: (CIMOSA)

Deleted: a 
and human and technical resource systems', Because of these dependencies it is required that in the life time of a ME, proper scientific tools be deployed to assist decision making. Literature in the domain of system dynamics and control engineering have shown that the structural and dynamic complexities involved in current markets can be found in the structure and processes of enterprises_Forrester 1961; Richardson 1999; Sterman 2000; Burns 2001). As a result of these dynamics, tools which are capable of modelling systems which mimic real life instances of change are essential for the sustainability of every ME in a fast changing market. Several different forms of visual mapping tool have been deployed, which are intended to help meet the above requirements (Hines and Nick 1997), But, it was observed that these techniques were designed to solve specific problems arising from different complexities in manufacturing systems. They were also observed to be 'static'. Consequently choice of mapping tool becomes a decisive issue for the user. |.

Efforts to classify processes in MEs have been reported by previous researchers (Chatha 2004, Two early classifications were provided by Salvandy and Pandya (Salvendy 1992; Pandya et al. 1997) It is observed that through the life time of any $\mathrm{ME}$, specific process changes may be required to be made to processes belonging to any of these process classes. The nature of the product types required, mixes of products, volumes and rate of supply will all impact on the required design of these processes. Also often changes made to any of the process threads will trigger correspondent causal and temporal effects in other process threads. This means that at each point in time, decisions have to be made based on some dynamic inputs which affect ME operations. Those dynamic changes cannot be captured adequately by static mapping tools. Hence with increased business fluidity, there has arisen a general need for tools capable of modelling and predicting outcomes from dynamic inputs to manufacturing enterprises.

Decisions made during process design will determine values and cost generated along process threads. In turn this partly determines the profitability of pusiness entities, Hence these are considered to be important decision variables. Companies

\begin{tabular}{l} 
Deleted: will \\
Deleted: any \\
Deleted: $y$ \\
\hline
\end{tabular}
that make the best decisions with regards to value creation and cost reduction normally win larger market shares. It is however not easy to make such decisions, because: 
1. When considering irregular market patterns and varying customer demands, it is relatively difficult to plan and operate manufacturing systems in such a way that optimisation of values and costs can be achieved over relatively short intervals.

2. Decisions made about re-design of one process thread has knock-on effects on other process threads. These threads will typically be resourced by combinations of human and technical resources and will normally have been designed and trained to achieve a given target. Reorganizing these resources demands application of an appropriate well-proven scientific methodology. Significant further complication arises because in some situations human and technical resources are shared by a number of process threads

3. Normally the adoption of any method demands an initial capital investment which may be difficult to justify, especially in an unstable market situation. Since businesses are often concerned primarily with short term profit margins. It follows that process design tools should make explicit those benefits to be obtained from such investments.

4. Coupled with (1) through (4), additional complications arise because decisions made, and new ME designs and implementations realised, will have a finite lifetime because of ongoing market and environmental changes that impact on the ME. It follows that ME design and change needs to be ongoing and that the adoption of appropriate means of systemising instances of ME design and change processes can prove highly beneficial, particularly if that systemisation is cognisant of factors that are most likely to require change (Rahimifard and Weston 2006)

\subsection{Research Approach Adopted}

Following up on previous enterprise and simulation modelling activities of researches at the MSI, Loughborough University, enhanced means of modelling dynamic value streams was conceived by analysing the complimentary strengths of lean manufacturing and enterprise engineering techniques. The objective here was to support each field with unique strengths of the other. Based on this background reasoning, the stepwise approach to dynamic value stream mapping described in overview by Table 1 was conceived and applied in case study MEs.

Key to the approach taken was identifying and using best-in-class decomposition techniques to represent complex manufacturing operations carried out in selected 
case study companies. However a subsequently developed aim was for these techniques to embed and help instrument the lean manufacturing philosophy such that they naturally transform static value stream models unto dynamic simulation models that can be used in most MEs that deploy multi-product dynamic manufacturing systems.

\begin{tabular}{|l|l|}
\hline Steps & Activity \\
\hline Step 1 & $\begin{array}{r}\text { Conduct literature review on: } \\
\text { - manufacturing strategies } \\
\text { - Jean Manufacturing } \\
\text { - enterprise integration and modelling techniques } \\
\text { - simulation modelling tools and application }\end{array}$ \\
\hline Step 2 & $\begin{array}{l}\text { Capture enterprise models of collaborating companies using } \\
\text { CIMOSA }\end{array}$ \\
\hline Step 3 & Derive 'static' value streams models of collaborating companies \\
\hline Step 4 & Derive and test dynamic models by building upon step 3 \\
\hline Step 5 & $\begin{array}{l}\text { General and specific recommendations with respect to area of } \\
\text { research }\end{array}$ \\
\hline
\end{tabular}

Table 1: Research approach adopted

\subsection{Description of the first case study problem domain studied}

The first case study company studied is a 'make-to-order' furniture company located in East Midlands of the United Kingdom. It operates with about fifty regular employees and uses basic furniture manufacturing equipment like sanders, grinders, polishes, benches, saws, planers, et cetera et cetera.

The company manufactures about three hundred different furniture products, ranging from different varieties of tables, cabinets, beds and wardrobes. The prime raw material is pine wood primarily supplied from the Scandinavian countries. A large majority of its products are sold through UK furniture stockists (i.e. distributors) who receive furniture from the case study company and other furniture making companies, for distribution to local stores.

The multi-product production system of this company consists of order processing; assembly; machining; painting; packaging and delivery units (see figure 1). Order 
processing is based on aggregating orders received from many stockists over specific timeframes. Orders received are grouped and transformed into 'runs'. These runs are based on the capacity of the fleet of transport vehicles owned by the company and logistical criteria related to the geographical location of customer stockists. These runs are converted unto a 'so called' picking list which specifies the furniture items that need to be manufactured and dispatched to the assembly section. On receipt of a picking list the assembly shop supervisor issues a mini-order to the machine shop on parts which need to be machined. The machine shop however usually makes predictions about assembly shop demands (based on experience) and therefore produces stockpiles of parts in racks located within the assembly shop. These stockpile can supply much of any current assembly shop demand but in general additional machining will be required when predictions are not accurate.

Figure 1: Schematic view of operations

Parts assembled are transferred to the painting shop. Finishing operations are performed on these sub-assembled parts as they are released from the painting shop, before final delivery. It takes approximately four weeks for picking list to be transformed into deliveries of products. This lead time changed significantly to eight weeks when there was an unexpected increase in customer demand. This was partially due to the company's inability to increase their ' effective' manufacturing capacity to match the customer demands.

Review of previous research work on the case study company showed that a lot of modelling work had already been done on the company. However critical investigation shows that the work was concentrated on process modelling, resource modelling, implementation and optimization of operations, testing and validating of existing and new modelling concepts. Hence the new dimension which is considered in this publication is the application of existing modelling techniques in the conceptualisation and application of models of dynamic value streams. This was required to help: 1)identify and analyse the value and non-value creation activities in the company; 2) identify and analyse impacts of queues/inventory levels and delays in the processes; 3) analyse effects of changes in values generated; 4) take into consideration 1) to 3 ) to recommend modelling formalisms capable of achieving better process efficiencies. 


\subsection{Value stream model of the case study company}

\subsection{System decomposition by the CIMOSA Modelling Technique}

Unlike current mapping schemes where mapping begins by associating customer orders with business operations and the supplier capabilities (Lee 2005) the Computer Integrated Manufacturing Open System Architecture, CIMOSA_approach to enterprise modelling represents MEs as a network of dependent processes $\underline{\underline{Z} \text { Zelm }}$ et al. 1995) Here processes are decomposed using well defined decomposition mechanisms, so as to create multi-perspective graphical models of various process segments of concern. Thereby process segments are modelled in the context of a specific business whilst being relatively easy to analyse and interpret. Another reason for adopting the CIMOSA modelling approach is that it naturally separates models of problems from models of solutions. In addition, these models gave an enhanced understanding of the company's business operations in visual form (although static and non-computer executable) demonstrating the flow of needed material, information and resource, and depicting interrelationships between these factors of production in the company.

A basic assumption made when applying the CIMOSA modelling technique is that it is appropriate to segment organisations into enterprise domains. Each enterprise domain has responsibility for one or more domain processes which communicate with other domain processes (belonging to the same and/or other domains) through events and results. Domain processes are further decomposed into business processes, which themselves comprise more elemental business processes and enterprise activities (Kosanke 1995; Berio and Vernadat 1999). Enterprise activities are considered to be atomic building blocks of domain and business processes, because they correspond to the lowest level of modelling abstraction considered by the enterprise modeller in the current modelling project.

Four types of CIMOSA diagramming templates, namely, 'context', 'interaction', 'structure' and 'activity' diagrams were used to coherently represent the various flows in the assembly shop of the company (Monfared 2000). Typically many instances of these template types are used in conjunction with a consistent numbering convention to provide a multi-perspective, graphical description of networks of processes used by any given target company. This was also the case for the company studied. 
Normally CIMOSA modelling commences by populating a context diagramming template to create a high level (abstract) model of the contributing enterprise domains (DMs) which eventually are 'actors' that contribute to a common process under study. In the case study company the main day to day operational processes are required to produce furniture to satisfy aggregated customer orders and to generate money values that create profit and pay for staff, space, machines, et cetera et cetera. The focus of this research was on modelling case study operate processes as discussed in the next sub sections. Normally the next CIMOSA modelling step is to create one or more interaction diagrams to explicitly and graphically specify needed communication links and physical exchanges between the domain processes; following which CIMOSA structure and activity diagrams are created to depict more detailed organisational relationships between Domain Processes (DPs), sequential and precedence Business Processes (BPs) and Enterprise Activities (EAs),

Figure 2 indicates the 'Top Level Context Diagram' which was created to imitate the operate processes of the case study company. Seven prime stakeholders were identified with respect to the case study organisation. The seven main enterprise domains were allocated a domain number and a decision was made to only model in detail the domain processes of DM7 and DM6. This decision was made because five of the contributing domains (and their associated organisational units) function externally with respect to the case study company and their operations are not under the control of that company. Because these domains were not modelled they are considered to be non-CIMOSA domains.

Figure 2: Top level context diagram

However it was understood when modelling that it might later prove beneficial to understand and capture models of external domains to satisfy their business purposes yet to be specified. DM6 and DM7 were subsequently decomposed into their respective domain processes, DP6 and DP7, as described by the subinteraction diagram in figure 3. 
The Interaction Diagram created explicitly describes interactions between the 'Produce and Deliver (DP7) domain process' and 'Business Management (DP6) domain process'. The resultant CIMOSA model shows current information about production schedules, delivery dates, picking lists and handling requirements, flow between these domain processes. Instances of DP7 and DP6 also need to interoperate with other domain processes such as DP2, 3 and 4, which constitute the supply of raw material, sub-products and miscellaneous fixtures, respectively. Resources such as fixtures, fittings and legs of tables flow from these suppliers to the 'Produce and Deliver' domain for necessary work to be done on them.

A sub-interaction diagram showing a further (and hence more detailed) decomposition of DP7 into its elemental Business Processes is shown for reference in figure 3. This shows five decomposed process segments concerned, namely: 'Make Furniture To Order (BP71); Spray and Finish Furniture Production (BP72); Package \& Deliver Furniture (BP73); Support and Implement Product Realisation (BP74); Maintain Production and Transport (BP75)'.

Figure 3: Sub-Interaction Diagram - DP7 decomposition

Structure diagrams were then created to document structural dependences between BPs and EAs related to DP7. This is shown in figure 4

Figure 4 Structure diagram for process segments comprising the 'Produce and Deliver Furniture' DP7

A significant number of activity diagrams were also created to detail relatively enduring temporal relationships between process and activity elements of the structure diagram, but in this paper only one segment of the 'Make and Deliver Parts' process is considered. In the case study, this Business process was required to 'Assemble carcasses and Fit components' (BP71-2). The process begins with the reception of a 'picking list' which specifies needed quantities of components for the assemblage. The human resources needed to realize the assembly process are basically Table Makers. Table consist of three subassemblies. They are the table top, under frame and legs sub-assemblies. 
As shown in the activity diagram in figure 5 , piano hinges are fitted to the top assembly and sent to the machine shop for shaping by the CNC Router. When this exercise is completed, the top is sanded by the Table Sander before spraying takes place at the spray shop. Miscellaneous bench work activities such as drilling, turning and components assembly take place in the assemblage of the under frame. When this is completed, the top sub assembly is assembled to the under frame subassembly and transferred to the spraying shop. In a similar fashion, bench work activities such as drilling, turning and sanding take place on the leg sub-assembly before it is transferred to the spraying shop. After the spraying of these sub assemblies, the legs are finally assembled to the top sub-assembly to achieve a complete Table.

Figure 5 Activity diagram

\subsection{Static Value stream model of selected process segment}

At the next stage of case study modelling activity diagrams of the assembly process were enriched semantically by attributing a new mapping scheme related to value Deleted: the streams. This was achieved by identifying the various cycle and queue times in the assembly process. Based on the market price of the products, values were estimated along the process thread. The cost of components associated with each of the activities were also estimated by considering the 'cost of buying' rather than making the components concerned. The ratio of cost to value was then used to achieve an assessment of the process efficiency for the process segment under consideration. Figure 6 shows a simplified value stream model of the assembly section of the case study company. It has been named a 'static value stream model' because it is limited in encoding time dependent instances and analysing variability over a given period. Because it uses the CIMOSA as the backbone model, the enterprise could be decomposed to its minute level of abstraction such that all functional operations are captured.

The upper part of the model shows a schematic diagram of all the interrelated enterprise domains. It serves as a guide to identify which area of the business needs to be decomposed. In a simplified form, it shows that the suppliers domains (DM1,2,3) need to interact with the technical operations (produce and deliver, DM7). 
Also the technical operations interact with customers or stockist (DM4) who also interact with the business management domain (DM6).

This model shows only BP71-2 which has been decomposed to its elemental EAs. All other domain and business processes have not been decomposed. This is to make the model fairly simple for analysis. Further decomposition of the processes can be done based on the objective of the modelling exercise.

Generally it was observed that the use of this modelling approach provided extra support to the existing mapping scheme. The additional capability arose because:

- It provided a holistic picture of the various operational activities that existed in the case study company.

- It enhanced the realization of future models based on the desire for process improvement

- The breaking down of the otherwise complex system of the case study company's business made it easy to understand how process segments were interrelated and hence the net effect of decisions made on one process thread. It formed a good basis to identify and demonstrate the likely consequences of changes in any of the enterprise input parameters

Notwithstanding, it was also observed that these models did not have sufficient ${ }^{+}$ semantics suitable for representing process changes and instances where process mixes and volumes are or could in the future be affected. Also alternative manufacturing, logistic and business policies could not be tested. It did not also provide specific process segments that need to be controlled or manipulated to achieve required mixes of products or process variation in attempt to meet varying customer or stakeholder requirements.

Figure 6 Current state map of assembly section

Formatted: Justified

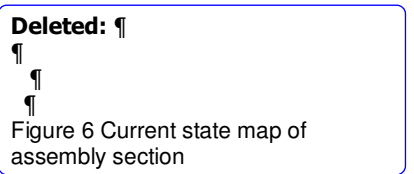

In view of the limitations identified, it was decided that since the end goal of this research is to be able to quantify business benefits through the achievement of values derived from alternative policies, it was necessary to transform this static 
model into computer executable models that do encode appropriate system dynamics and that can be tested using a proprietary simulation software.

\subsection{Dynamic value stream model}

Up to this point, a static model representing the flow of historical production data through a selected process segment of the case study company had been created and used to inform decision making about process efficiency, etc. Despite its static nature this provided a rich coherent source of information for visualising interrelated processes necessary to assemble tables. However, in the real case ME it was necessary to realise economies of scope by assembling various types of table in dynamic (constantly changing) quantities and mixes necessary to satisfy customer orders. This was observed to give rise to dynamic instances of interactions between product elements, process elements and their underpinning resource elements, and it becomes difficult to visualise and specify needed changes to ME processes using such a static model_(Rahimifard and Weston 2006). Because of the need to share resources, coupled with varying customer needs and dynamic environmental 2006)

Formatted: Not Highlight conditions, significant complexity was introduced with respect to planning and controlling production.

Previous work by the authors have indicated that some types of changes that normally have influence over common operational processes of MEs can be expressed as shown in figure 7. These changes may be classified as

- Process-oriented changes - (such as process instances, process logic, flow Deleted: Weston Deleted: (Weston, Rahimifard et al. 2007) explained controls and the required roles and relationships)

- Product-oriented changes - (such as product properties, product mix, product volumes, material availability)

- People (and related mechanical resource)-oriented changes - (such as resource availabilities, resource competencies and capacities, resource controls and resource organisation)

In general selected process variables (or elements) belonging to each class can be used as control levers that affect other process variables (or elements) so as to make required process improvements. However the extent to which that is true in the real case will be dependant upon natural phenomenon and constraints that link the 
variables. Hence in practice only some control variables can be chosen and only constrained ranges of adjustment to them can be made.

Figure 7 Types of changes on MEs,

To analyse the effect of some of these variables on the static value stream model, system dynamics modelling in the form of dynamic causal loops was deployed to model salient processes (BP's) of the assembly process (see figure 8). The system dynamics modelling technique adopts causal loop modelling and stock and flow diagrams to analyse complex business problems (Randers 1980). These modelling frameworks are supported by strong non-linear complex mathematical theories and control engineering principles (Forrester 1961; Burns 2001). The modelling technique relies on the fact that 'current reactions are based on past actions' (Forrester 1961) indicating that 'there are causal relationships between actions and reactions'. Sterman (Sterman 2000), noted that 'most unexpected challenges are as a result of past actions'.

Causal loop modelling have long been used in standard system dynamics practice for purposes connected to simulation modelling Basically, it contains variables, and arrows which show the causal relationships between the variables. Increasingly they are now being used to depict the basic causal mechanisms hypothesized to underlie reference mode of behaviour over time, that is for articulation of a dynamic hypothesis of the systems as endogenous consequences of the feed back structure (Richardson 1999). They have been know to be excellent for:

1. depicting relationships between cause and possible effects, 2001)

2. creating dynamic models of businesses for alternative policy verification (Wolstenholme 1999; Homer and Oliva 2001)

Field Code Changed

Deleted: (Forrester 1961; Backhouse and Burns 1999; ScholzReiter and Schmieder 2003)

Field Code Changed

Field Code Changed

Field Code Changed

Deleted: (Sterman 2000)
Field Code Changed

Field Code Changed

Deleted: (Homer and Oliva 2001; Haraldsson 2004)

Field Code Changed

Field Code Changed

Deleted: (Weston 2005)

Formatted: Not Highlight 
Causal loop modelling starts with a variable followed by an arrow which shows the causal links with its effect. Each causal link is denoted by a positive or negative polarity to represent how the variables change in respect to the other. A loop is called positive, regenerating or reinforcing if it has no negative polarized links or if the sum of the negative links is even. Otherwise it is a negative or balancing loop.

Thinking about the influence loops described in figure 8 coupled with understandings gained by observing active assembly operations, it can be realised from studying balancing loop 1 (B1) that increase in number of CNC operations increases number of set-up operations which also increase the total set up delays. Set up delays lead to high lead times. The high lead time tends to increase the queue time as well. This is a reflection of the current state of the company since other products are also fed to the CNC router which tend to block the free utilisation of the CNC router for dedicated assembly process jobs. Hence significant long queues resulted in the excessive lead times associated with CNC operations.

A study of balancing loop 2 (B2) shows the effect of increase in number of operations. Over here resources have to be allocated to meet the increase in operations. In general these resources include human and technical resource elements and also material handling elements used during travel processes. Resource cost therefore increases causing a reduction in the process efficiency over a short period. Also as a result of the frequent movements low process efficiency was realised from waste due to transportations derived from the number of movements and also the distance of movements. From balancing loop 3 (B3), it is evident that process cost will increase as a result of increase in travel times, increase in cost associated with quality inspection and set up. Other factors known to affect process cost are direct labour and overhead costs, Also observed is that process cost will reduce as waste due to defects is reduced. This is depicted by balancing loop 4 (B4). It can therefore be understood that the transfer of partial assemblies for further operations in the machine shop has a retrogressive effect on process lead time and cost, as predicted by the loops.

Figure 8: Influence loop 1 
Another influence loop shown in figure 9 relates to the assembly of under frames to the table top. From these loops it can be derived that there is a need to increase the flow of stock to the spray shop through efficient business operations, since this reduces the idle time of sprayers and spraying equipment. The use of jigs and fixtures facilitate the assembly rate by reducing the lead time, thereby increasing the efficiency of the assembly process. There are also potential instances of untimely supply of sub assemblies to the assembly shop due to the occurrence of long queues at the machine shop $\mathrm{CNC}$ router.

Figure 9 Influence loop 2 for decision making

It is important to note that although the causal loop models gave indicative responses to changes, they were not parametric. Hence on their own they could not quantify the effect of changes on the enterprise.

\subsubsection{Dynamic simulation model of the assembly section of case study company}

In view of the limitation on the dynamic causal loop modelling technique and the underlining vision of quantifying business benefits that could arise from making manageable ME changes to process structures, product and material flows, resource assignments and the like, simulation models which replicate process behaviours of the assembly shop of the case study company were created. This was done so that the assumptions, parameters and data incorporated into these models could be verified. When this is verified, the models can be used to predict better ways of optimising process designs and performance.

In practice fair conclusions can be drawn about a system after studying the system's response to actions over a sufficient long period (Carrie 1988; Mertins et al. 2000). Simulation modelling techniques feature well in imitating systems behaviour over a period of time. Research work by the authors and their colleagues in the Manufacturing System Integration (MSI) Research Institute of Loughborough University have identified that visual and graphical simulation modelling methods often deployed in modelling aspects of manufacturing processes utilize either discrete event or continuous simulation tools. In this paper one of the discrete event simulation tools, namely 'Simul8' (Shalliker et al. 2005) was used to (1) replicate and

Deleted: $A$

Field Code Changed

Deleted: (Shalliker, Rickets et al. 2005) 
understand current process behaviours generated by the assembly shop and (2) identify and quantitatively model value streams generated along the process threads (3) deploy knowledge gained from (1) and (2) to inform decision making about what are potentially manageable ME changes in respect to the case study companies value streams.

In theory simulation modelling enhances enterprise modelling by helping solve the problems of:

Deleted: $\mathrm{E}$

Deleted:

- System dimensioning,

- Parameter optimisation,

- Design of control policies,

- System operation checking,

- Performance evaluation,

- Comparison of several design alternatives to select the most suitable one (Vernadat 2002).

Field Code Changed

This was the fundamental assumption upon which the simulation modelling presented in this paper was built. Also, it was assumed that the static value stream model already created could conveniently be transformed into equivalent simulation models. Much of the data required for the development of such a simulation model had already been encoded by the static value stream model. Importantly the static model described the sequence of processing activities necessary to derive the output. Associated information, material and control flows were also encoded in outline. Additional information which was captured in order to successfully create the simulation model included: actual processing times, resource and task allocation, product or process routings, machine sharing mechanisms, setup times and history of machine failures. Figure 10 shows a snapshot of the simulation model of the assembly shop operation created by using Simul 8 software.

Figure 10 Snapshot of the Simul 8 model

A critical assessment of results derived from the simulation model enabled prediction

Deleted: these and verification of current bottleneck activities. This concerned operations at which delays caused longest queue times. Delays at bottleneck operations subsequently

08/07/2010 
affected the total processing time of the complete process, The total lead time and value generated by the modelled processes was found to mirror those historically observed in the real case enterprise and thus the model was noted to be a true reflection of the real life case study.

Three sets of experiments were conducted using the model after it had been validated. These were specially designed experiments to analyse the impact of manageable ME changes. These experiments also helped identify ways of achieving reduced lead times and improved value streams in attempt to demonstrate the generic change effects depicted by the causal loop models, already described. These experimental sets related respectively to (i) product changes due to varying customer requirements, (ii) people resource changes and (iii) related mechanical resource change.

A number of parametric changes were made to the way in which human resources were assigned to units of work; with a view to monitor and analyse effect these changes had on the process and thereby, determine potential benefits that alternative work assignments might bring to the case study company. The first situation experimented was to change the work roles and the nature of work done. Extra work loads were added, because it was observed that the resources, especially at the bench sections were grossly underutilised. It was also decided to maximize the work in the system. The results proved worthwhile. The average resource utilization rose from $34 \%$ to $72 \%$, whilst the output showed a gradual increase. It follows that by systematically increasing the work load, a corresponding output can be expected.

An important aspect which was experimented was increasing the number of product Deleted: trialled variances at the process entry point. The model demonstrated a degree of 'malfunctioning' as there was complications in resource sharing (both human and technical). Therefore in the simulation models already created, rules related to prioritization were established such that the model was able to identify the different products in the system. This tends to suggest that in real world multi-product flow systems where products arrive at undetermined intervals, further complications are to be expected, if the ME is not designed to cope with product variances. This related idea establishes the need for 'reconfigurable, recomposable and reprogrammable' ME models which have the capability to cope with changes in multiple product flows.

\begin{tabular}{l} 
Deleted: are \\
Deleted: ing \\
Deleted: ing \\
Deleted: ve \\
Deleted: to \\
\hline
\end{tabular}

Deleted: trialled was

Deleted: which product to attend. 
Coherently, when the rate of flow of product components was altered, it was observed that significant improvements were realised, predicting the fact that alternative arrangements of the flow of products inputs can affect the ultimate fulfilment of the product or customer order, avoiding excessive delays and inventory accumulation. Table 2 shows significant process improvements that can be obtained by reducing the rate of processing of one of the components in the assembly shop.

\begin{tabular}{|c|c|c|c|c|c|c|c|c|}
\hline Simulation Object & $\begin{array}{l}\text { Performance } \\
\text { Measure }\end{array}$ & \multicolumn{5}{|c|}{ Experimental results } & $\begin{array}{l}\text { Average } \\
\text { value }\end{array}$ & $\begin{array}{l}\% \text { Process } \\
\text { improveme } \\
\text { nt achieved }\end{array}$ \\
\hline $\begin{array}{l}\text { 'bench-finish' } \\
\text { operation ('as-is') }\end{array}$ & $\begin{array}{l}\text { Average } \\
\text { queue size }\end{array}$ & 18.0 & 22.6 & 16.4 & 16.4 & 26.2 & 19.9 & \multirow{4}{*}{$87.94 \%$} \\
\hline \multicolumn{2}{|c|}{$\begin{array}{l}\text { Current state ('as-is') inventory cost in } \\
\text { pounds (approximate value) }\end{array}$} & 300 & 400 & 300 & 300 & 400 & 300 & \\
\hline $\begin{array}{l}\text { Queue for } \\
\text { 'bench-finish' } \\
\text { operation ('to-be') }\end{array}$ & $\begin{array}{l}\text { Average } \\
\text { queue size }\end{array}$ & 2.5 & 3.0 & 0.1 & 0.0 & 6.5 & 2.4 & \\
\hline $\begin{array}{l}\text { Future state ('to-b } \\
\text { pounds (approxima }\end{array}$ & $\begin{array}{l}\text { entory cost in } \\
\text { ue) }\end{array}$ & 0.0 & 100 & 0.0 & 0.0 & 100 & 0.0 & \\
\hline
\end{tabular}

Table 2 Results for queue size at bench finish area only

A key parameter which was identified as being critical to improving the value generated by the whole process was by reducing the rate of entry of table tops. When this was experimented, the queue at the CNC operation was drastically reduced without affecting the output quantities.

In summary results from the influence of the planned ME changes in view of ensuring better process efficiency ensured that in the revised value stream model human resources were fully utilised, work benches were not idle, inventory cost was reduced by $60 \%$, and overall process improvement amounted to $70.4 \%$

\subsection{Observations and discussions}

Throughout this study, it was observed that there was the need for adequate data Deleted: collection to enable successful implementation of the techniques recommended in the paper. 
The CIMOSA templates and modelling constructs aided the value stream mapping technique by providing an effective and reusable way of decomposing complete networks of enterprise functionalities into process segments at some level of abstraction. In addition it gave a solid foundation upon which the simulation models were generated. It hence served as the backbone model for the creation of simulation models.

Although the benefits of the static value stream model can not be doubted, it was, observed that it could not be used to mimic or predict relative ME behaviours, especially related to change. It was also realised during the modelling exercise that, it took relatively longer time to 1) capture information from the case study company; 2 ) populate the modelling templates; 3 ) validate and finalise the modelling templates; before a comprehensive acceptable enterprise model could be derived and used for generating static value stream models. From experience in this modelling exercise, it is worth noting that in MEs where enterprise models have been developed already, the compounded problem of working with an inaccurate model is real. However jn instances where CIMOSA models have not yet been constructed, it is appropriate to narrow down the modelling requirements such that only the area of interest would be focussed on. Essentially this modelling approach has the capability of being used as a check over results derived from existing value stream mapping technique.

Results of the research proved that it was possible to analyse the dynamic impacts of enterprises with respect to value streams derived along process segments. Also system dynamics could fairly be experimented, although with well controlled and expected change variables.

Collectively, the populated models provided an integrated view forming the basis of knowledge sharing about the ME and its environment which can inform decision making about process improvement, resource allocation, manufacturing synchronisation policies, re-organization of the entire supply chain, evaluation of manufacturing lead time, total system output and total work-in-place, change and so forth.

The causal loop modelling technique gave indications as to potential change parameters of the assembly section of the case company. The results obtained 
proved beneficial. They qualitatively predicted possible outcomes of change actors in Deleted: ing the company.

Modelling value streams by the approach described in this paper ensured that the conventional value stream mapping technique, derived from lean thinking, was enhanced with the enterprise modelling technique, CIMOSA. This was further enriched with concepts of system dynamics, which helped in analysing the possible impact of change on the existing variables of the case company. With the successful transformation of aspects of the static models to dynamic simulation models, it was possible to analyse the impact of alternative management policies or decisions on values generated along selected process segments of the company. These benefits could not be obtained from the static value stream maps.

Hence it is deduced that for most MEs deploying multi-product flows in dynamic markets, it is more appropriate for their systems to be modelled comprehensively through the application of the enterprise modelling approach. Otherwise the tendency of overlooking salient aspects of process segments during mapping can be high. In addition to the static modelling approach ${ }_{2}$ it is beneficial to transform the static models to dynamic models to enable dynamic assessments to be conducted on the models before implementation. This can support companies to make economic analysis of policies and solutions before their implementation.

\section{Conclusion}

Some of the challenges facing MEs include the scientific testing of ideas or decisions and also the ability to analyse the impact of possible change parameters on MEs. These decisions invariably affect process designs which in turn impact significantly on outputs, timeliness, and competitiveness of companies. An approach for evaluating decisions and changes that affect the generation of values in MEs has been described in this paper. The relative strengths of this modelling technique have also been discussed, taking particular notice of the suitability of transforming static value stream models into dynamic models capable of replicating real enterprise behaviours. The challenge of creating a valid enterprise model js real and measures must be taken so that models which serve as backbones of dynamic models are accurate, else the tendency of working and making inaccurate recommendations can not be avoided.

\begin{tabular}{l}
\hline Deleted: framework \\
\hline Deleted: dynamically \\
\hline Deleted: the \\
\hline Deleted: s \\
\hline Deleted: thinking methodology which \\
Deleted: The transformation of the \\
gave the possibility of \\
\hline Deleted: ing \\
\hline Deleted: process segments of \\
\hline Deleted: sections \\
\hline Deleted: is \\
\hline Deleted: in the \\
\hline Deleted: existing literature describe. \\
\hline Deleted: a \\
\hline Deleted: by the \\
\hline Deleted: important \\
\hline Deleted: ould \\
Deleted: from spending monies to \\
implement decisions which will not be \\
economically viable \\
process thread can be captured fully \\
recommended in this paper. \\
\hline
\end{tabular}

\section{Deleted: Two}

Deleted: made in MEs

Deleted: ing

Deleted: in organizations

Deleted: will

Deleted: the

Deleted:

Deleted: to

Deleted: of a given process segment under consideration

Deleted: that

Deleted: the

Deleted: the

Deleted: disaster

Deleted: proposing conclusions based on inaccurate data 
The enterprise modelling approach in support of value stream mapping ensured that systems were decomposed in a way that semantic rich and coherent understandings about relatively enduring aspects of the enterprise could be derived. Despite the limitation of this approach (as explained in previous sections) it provided a strong foundation for the development of dynamic models of the value streams of the case study company. Separate literature have attempted to describe how static models can be usefully transformed to dynamic simulation models (Scheer 1994; Chatha and Weston 2005; Rahimifard and Weston 2006). It is envisaged that the accurate deployment of ideas described in this paper will definably jmprove knowledge about process design and their evaluation in MEs. The authors in relation to their ongoing research work in the area of value and cost dynamics, aim to derive $\underline{a}$ comprehensive alternative generic value stream and cost modelling methodology which will support MEs engaged in multi-product flow processes and operating in dynamic market environments. When these useful dynamic models are generated, they will aid decision making with regards to alternative variables which affect values, cost and process efficiencies.

\section{References}

AMICE (1993). CIMOSA: Open System Architecture for CIM, 2nd ed. Berlin, Springer-Verlag.

Askin, R. (1993). Modelling and analysis of manufacturing systems. New York, Wiley.

Berio, G. and F. B. Vernadat (1999). "New developments in enterprise modelling using CIMOSA." Computers in Industry 40(2): 99-114.

Bernus, $P$. and L. Nemes (1996) $)^{-}$Enterprise integration-engineering tools for designing enterprises. IFIP TC5 Working Conference on Models and Methodologies for Enterprise Integration. Australia, Chapman \& Hall.

Bernus, P. and L. Nemes (1996b). "A framework to define a generic enterprise reference architecture." Computer Integrated Manufacturing Systems 9(3): 179-191.

Bicheno, J. (2000). The Lean Toolbox, 2nd ed. Buckingham, PICSIE Books.

Burns, J. R. (2001). Simplified translation of CLDS into SFD́ Proceedings of the 19th International conference of the System Dynamics Society, Atlanta, GA.

Carrie, A. (1988). Simulation of Manufacturing Systems. Chichester, Wiley.

CEN/ISO (19440). "Enterprise integration - Constructs for modelling."

Chatha, K. A. (2004,). "Multi-process modelling approach to complex organisation design, PhD. Thesis." Loughborough University.

Chatha, K. A. and R. H. Weston (2005). "Combined Enterprise and Simulation modelling in support of process engineering." "Int. Journal of CIM 18(8): 652$\underline{670 .}$

Doumeingts, G., D. Chen, et al. (1992). GRAl- A method for designing CIM systems. France, GRAI/LAP, University of Bordeaux.

Deleted: to deriving static

Deleted: s assisted

Deleted: by ensuring that

Deleted: (Chatha, Ajaefobi et al

2005; Rahimifard and Weston 2006)

Formatted: Not Highlight

Deleted: spelt out

Deleted: affect

Deleted: es

Deleted: , their relative strengths

and capability of responding to

change actors.

Deleted: propose base on this paper and

Deleted: an

Deleted: deploying

Deleted: also MEs engaged in

Deleted: So that

Deleted: can be generated

Deleted: for enterprises to

Formatted: Underline

Formatted: Underline

Formatted: Underline

Formatted: Font: Bold

Formatted: Underline

Formatted: Underline

Formatted: Font: Bold

Formatted: Underline

Formatted: Underline

Formatted: Underline

Formatted: Underline

Formatted: Underline

Formatted: Font: Bold 
Duggan, K. (2002). Creating mixed model value streams. New York, Productivity press.

Ferreira, P. and J. M. Mendonca (1994). Using a Decision Suppport System for CIM System Life Cycle Support. Proceedings of the IFIP WG5.7 Working Conference on Evaluation of Production Management, Amsterdam, North Holland Publishing Company.

Forrester, J. W. (1961). Industrial Dynamics, MIT Press.

Hines, P. and R. Nick (1997). "The seven value stream mapping tools." International Journal of Operations and Production Management 17(1): 46-64.

Homer, J. and R. Oliva (2001). "Maps and models in system dynamics: a response to Coyle." System dynamics review 17: 347-355.

Kosanke, K. (1995). Process oriented presentation of modelling methodologies. Proceedings of the IFIP TC5 Working conference on models and methodologies for Enterprise Integration, Australia, Chapman \& Hall.

Lee, G. (2005). Strategos guide to Value Stream and Process Map. Strategos International, ÚSA, Engineering and Management Press.

Lutherer, E., S. Ghroud, et al. (1994). Modelling with CIMOSA: a case study. Proceedings of the IFIP WG5.7 Working Conference on Evaluation of Production Management Methods, Amsterdam, Elsevier.

Mendonca, J. M., J. W. Schulte, et al. (1993). Real time shop floor control: modular system and integration tools. Proceedings of the 9th CIM-Europe annual conference on Realising CIM's industrial potential, Amsterdam, IOS Press.

Mertins, K. and R. Jochem (1996). Integrated enterprise modelling for business process reengineering. Proceedings of the IFIP WG5.3 international conference on Life-cycle modelling for innovative products and processes, Berlin, Chapman \& Hall.

Mertins, K., M. Rabe, et al. (2000). Neutral template libraries for efficient distributed simulation within a manufacturing system engineering platform. Proceedings of the 32nd conference on winter simulation., Orlando, Florida, Society for Computer Simulation International.

Monfared, R. P. (2000). "A Component Based Approach to Design and Construction of Change Capable Manufacturing Cell Control Systems." PhD Thesis, Loughborough University, UK.

Pandya, K. V., A. Karlsson, et al. (1997). "Towards the manufacturing enterprises of the future." International Journal of Operations and Production Management 17: 502-521.

Rahimifard, $\bar{A}$. and $R$. Weston (2006). "The enhanced Use of Enterprise and Simulation Modelling Techniques to Support Factory Changeability." Int. Journal of CIM 20(4): 307-328.

Randers, J. (1980). Elements of the system dynamics method. Cambridge, $\mathrm{MA}, \overline{M I T}$ press.

Richardson, G. P. (1999). "Reflections for the future of system dynamics." Journal of Operational Research Society 50: 440-449.

Salvendy, G. (1992). Handbook of Industrial Engineering. New York, Wiley.

Scheer, A. W. (1992). Architecture of Integrated Information Systems, Foundation of Enterprise Modelling. Springer-Verlag.

Scheer, A. W. (1994). "ARIS Toolset: a software product is born." Special issue: Distributed information systems in business and management 19(9): $607-62 \overline{4}$.

Shalliker, J., C. Rickets, et al. (2005). An Introduction to SIMUL8 (Release 12), SIMUL8 Corporation.

Sterman, J. (2000). Business Dynamics: Systems thinking and modeling for a complex world, "McG̈raw Hill.

Modelling dynamic value streams $\quad 24$

$08 / 07 / 2010$
Formatted: Underline

Formatted: Underline

Formatted: Underline

Formatted: Underline

Formatted: Font: Bold

Formatted: Underline

Formatted: Font: Bold

Formatted: Underline

Formatted: Underline

Formatted: Underline

Formatted: Underline

Formatted: Underline

Formatted: Underline

Formatted: Underline

Formatted: Underline

Formatted: Font: Bold

Formatted: Underline

Formatted: Font: Bold

Formatted: Underline

Formatted: Underline

Formatted: Font: Bold

Formatted: Underline

Formatted: Underline

Formatted: Underline

Formatted: Font: Bold

Formatted: Underline

Formatted: Underline 
Vernadat, F. B. (1996). Enterprise modelling and integration; Principles and Applications. London, Chapman \& Hall.

Vernadat, F. B. (2002). "UEML: towards a unified enterprise modelling language." Int. J. of Production Research 40(17): 4309-4321.

Williams, T. J. (1992). The Purdue Enterprise Reference Architecture. Instrument Society of America, North Carolina.

Williams, T. J. and H. Li (1998). PERA and GERAM - Enterprise Reference architecture for Enterprise Integration. Proceedings of the IFIP $3 \mathrm{rd}$ international working conference on the design of information infrastructure systems for manufacturing II, Netherlands, Kluwer, B.V.

Wolstenholme, E. F. (1999). "Qualitative verses quantitative modelling: the evolving balance." Journal of Operational Research Society 50: 422-428.

Womack, J. and D. Jones (2003). Lean-Thinking - Banish Waste and Create Wealth in Your Corporation. New York, Free Press.

Womack, J., D. Jones, et al. (1990). The Machine that Changed the World: The Story of Lean Production. New York, Rawson Associates.

Zelm, M., F. B. Vernadat, et al. (1995). "The CIMOSA business modelling process." Computers in Industry 27(2): 123-142.
Formatted: Underline

Formatted: Underline

Formatted: Font: Bold

Formatted: Underline

Formatted: Underline

Formatted: Underline

Formatted: Font: Bold

Formatted: Underline

Formatted: Underline

Formatted: Underline

Formatted: Font: Bold

Formatted: Indent: Left: $0 \mathrm{pt}$, First line: $0 \mathrm{pt}$

Deleted: Askin, R. (1993). Modelling and analysis of manufacturing

systems, John Wiley \& Sons. ๆ

Backhouse, C. J. and N. D. Burns

(1999). "Agile Value Chains for

Manufacturing-Implications for

performance Measures." Int. J. of

Agile Management Systems: 76-82.

Bermus, P. and L. Nemes (1996). "A

framework to define a generic

enterprise reference architecture." Int.

J. of CIM.T

Bernus, P. and L. Nemes (1996).

Enterprise integration-engineering

tools for designing enterprises.

Bicheno, J. (2000). The Lean

Toolbox. Buckingham, England,

PICSIE Books. ๆ

Binder, T., V. Andreas, et al. (2006).

"Developing system dynamics models

from CLDs." $\Phi$

Carrie, A. (1988). Simulation of

Manufacturing Systems. USA, John

Wiley \& Sons. $\llbracket$

CEN/ISO (19440). "Enterprise

integration - Constructs for

modelling."

Chatha, K. A. (2004,). "Multi-process

modelling approach to complex

organisation design, PhD. Thesis."

Loughborough University. 1

Chatha, K. A., J. O. Ajaefobi, et al.

(2005). "Enriched multi-process

modelling in support of the life cycle

engineering of business processes." $\mathbb{q}$

Chatha, K. A., R. H. Weston, et al.

(2003). "An approach to modelling

dependencies linking engineering

processes." Proceedings of Institution

of Mechanical Engineers Part B:

Journal of Engineering Manufacture. I

CIMOSA (1993). ESPIRIT CIMOSA

Standards, CIMOSA: Open System

Architecture for CIM. Spinger-Verlag. .

Architecture for CIM. Sping

Association " CIMOSA: A primer on

Key Concepts, Purpose and Business value

I

Doumenigts, G., D. Chen, et al.

(1992). GIM- a GRAI integrated

methodology. A method for des ... [1]

Formatted: English (U.K.)

Formatted: English (U.K.) 
List of Figures

Figure 1 Schematic view of operations

Figure 2 Top Level Context diagram

Figure 3 Sub-Interaction diagram

Figure 4 Structure diagram for process segments comprising the 'Produce and Deliver Furniture' DP7

Figure 5 Activity diagram

Figure 6 Current state map of assembly section

Figure 7 Types of changes on MEs

Deleted: (Weston, Rahimifard et al.

Figure 8 Influence loop 1

Figure 9 Influence loop 2 for decision making

Figure 10 Snapshot of the Simul 8 model 
Page 25: [1] Deleted

Staff/Research Student

8/1/2008 11:04:00 PM

Askin, R. (1993). Modelling and analysis of manufacturing systems, John Wiley \& Sons.

Backhouse, C. J. and N. D. Burns (1999). "Agile Value Chains for ManufacturingImplications for performance Measures." Int. J. of Agile Management Systems: 76-82.

Bermus, P. and L. Nemes (1996). "A framework to define a generic enterprise reference architecture." Int. J. of CIM.

Bernus, P. and L. Nemes (1996). Enterprise integration-engineering tools for designing enterprises. Australia, Chapman \& Hall.

Bicheno, J. (2000). The Lean Toolbox. Buckingham, England, PICSIE Books.

Binder, T., V. Andreas, et al. (2006). "Developing system dynamics models from CLDs."

Carrie, A. (1988). Simulation of Manufacturing Systems. USA, John Wiley \& Sons.

CEN/ISO (19440). "Enterprise integration - Constructs for modelling."

Chatha, K. A. (2004,). "Multi-process modelling approach to complex organisation design, PhD. Thesis." Loughborough University.

Chatha, K. A., J. O. Ajaefobi, et al. (2005). "Enriched multi-process modelling in support of the life cycle engineering of business processes."

Chatha, K. A., R. H. Weston, et al. (2003). "An approach to modelling dependencies linking engineering processes." Proceedings of Institution of Mechanical Engineers Part B: Journal of Engineering Manufacture.

CIMOSA (1993). ESPIRIT CIMOSA Standards, CIMOSA: Open System Architecture for CIM. Spinger-Verlag.

CIMOSA (1996). "CIMOSA Association " CIMOSA: A primer on Key Concepts, Purpose and Business value

Doumenigts, G., D. Chen, et al. (1992). GIM- a GRAI integrated methodology. A method for designing CIM systems. France, GARI/LAP, University of Bordeaux.

Duggan, K. (2003). Creating mixed model value streams. USA, Productivity press.

Ford, A. (1999). "Modelling the environment: An introduction to system dynamics models of environmental systems." Island Press, Washington D.C.

Forrester, J. W. (1961). Industrial Dynamics, MIT Press.

Haraldsson, H. V. (2004). "Introduction to systems thinking and causal loop diagrams." Technical report, Lund University, Department of Chemical Engineering. Reports in ecology and environmental engineering: 1-49.

Hines, P. and R. Nick (1997). "The seven value stream mapping tools." International Journal of Operations and Production Management 17(1): 46-64.

Hines, P. and D. Taylor (2000). Going Lean. Lean Enterprise Institute. Cardiff Business School, UK.

Homer, J. and R. Oliva (2001). "Maps and models in system dynamics: a response to Coyle." Systems Dynamics Society 17: 347-355. 
Kosanke, K. (1996). "Process oriented presentation of modelling methodologies." Proceedings of the IFIP TC5 Working conference on models and methodologies for Enterprise Integration: 45-55.

Lee, G. (2005). Strategos guide to Value Stream and Process Map. Strategos International, USA, Engineering and Management Press USA.

Lutherer, E., S. Ghroud, et al. (1994). "Modelling with CIMOSA: a case study." Proceedings of the IFIP WG5.7 Working Conference on Evaluation of Production Management Methods B-19: 195 - 203

Monfared, R. P. (2000). "A Component Based Approach to Design and Construction of Change Capable Manufacturing Cell Control Systems." PhD Thesis, Loughborough University, UK.

Pandya, K. V., Karlsson, A., Sega, S. and Carrie (1997). "Towards the manufacturing enterprises of the future." International Journal of Operations and Production Management 17: 502-521.

Rahimifard, A. and R. Weston (2006). "The enhanced Use of Enterprise and Simulation Modelling Techniques to Support Factory Changeability." MSI Research Institute, Loughborough University, UK.

Randers, J. (1980). "Elements of the system dynamics method." MIT Press, Cambridge, MA.

Richardson, G. P. (1999). "Reflections for the future of system dynamics." J. of the Operational Research Society(50): 440-449.

Salvendy, G. (1992). Handbook of Industrial Engineering. New York, Wiley.

Scheer, A. W. (1992). Architecture of Integrated Information Systems, Foundation of Enterprise Modelling. Springer-Verlag.

Scholz-Reiter, B. and F. A. Schmieder (2003). Modelling and control of production systems based on nonlinear dynamics theory. Department of Planning and Control of Production Systems, University of Breman, Breman, Germany.

Shalliker, J., C. Rickets, et al. (2005). An Introduction to SIMUL8 (Release 12), SIMUL8 Corporation.

Sterman, J. (2000). Business Dynamics: Systems thinking and modelling for a complex world, McGraw Hill.

Vernadat, F. B. (1996). Enterprise modelling and integration; Principles and Applications, Chapman \& Hall, London.

Vernadat, F. B. (2002). "UEML: towards a unified enterprise modelling language." Int. J. of Production Research 40(17): 4309-4321.

Vernadat, G. B. a. F. B. (1999). "New developments in enterprise modelling using CIMOSA." Computers in Industry 40(2): 99-114.

Weston, R. (2005). Unified Modelling of Complex Systems - to facilitate ongoing organisation design and change Loughborough University, UK.

Weston, R. (2006). "Enterprise modelling in support of global manufacturing." MSI Research Institute, Loughborough University.

Weston, R., A. Rahimifard, et al. (2007). Next Generation, Change Capable, Component Based Manufacturing Systems: Part 1 Dynamic Producer Unit Loughborough University, UK. 
Weston, R. H., A. Rahimifard, et al. (2007). "Model Driven Manufacturing Organisation Design and Change." Loughborough University, UK.

Williams, T. J. (1992). "The Purdue Enterprise Reference Architecture." Instrument Society of America. Research Triangle Park, North Carolina, USA.

Williams, T. J. (1998). "PERA and GERAM - Enterprise Reference architecture for Enterprise Integration."

Wolstenholme, E. F. (1999). "Qualitative verses quantitative modelling: the evolving balance." J. of the Operational Research Society 50: 422-428.

Womack, J. and D. Jones (1996). Lean-Thinking - Banish Waste and Create Wealth in Your Corporation. New York.

Womack, J. P., D. Jones, et al. (1990). The Machine that Changed the World: The Story of Lean Production. New York, Rawson Associates.

Zelm, M., et al (1995). "The CIMOSA Modelling process." Computers in Industry. 


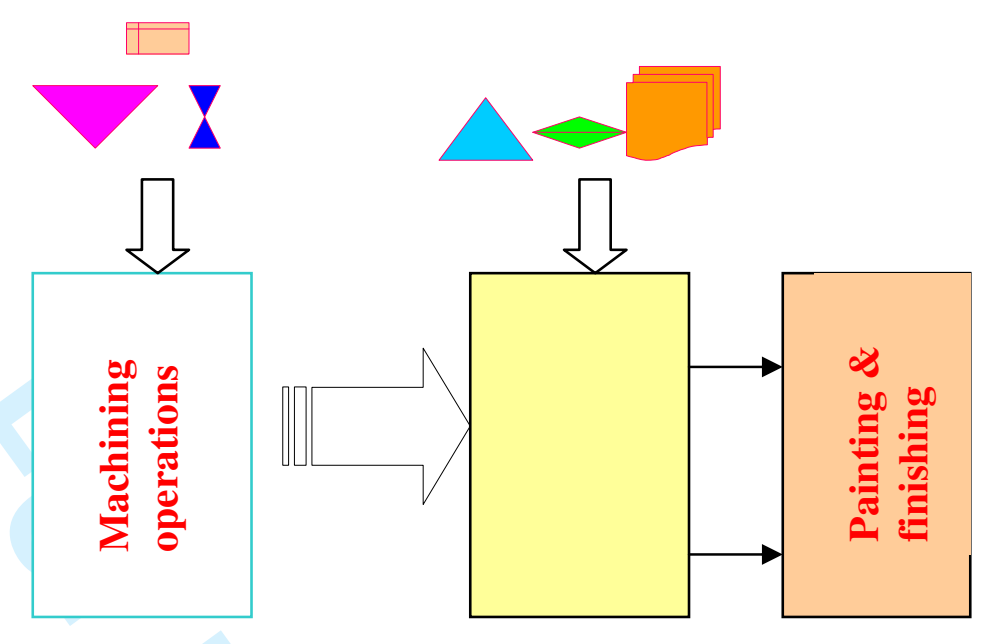

Figure 1: Schematic view of operations

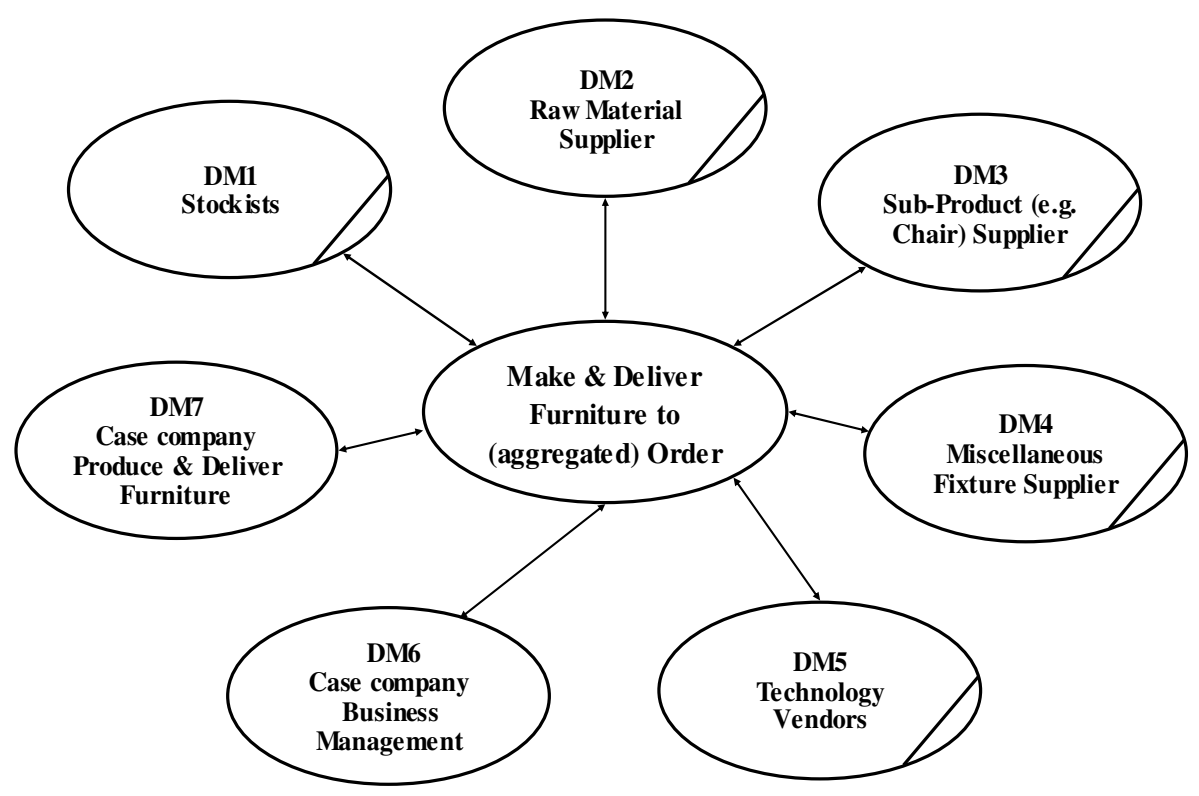

Figure 2: Top level context diagram 


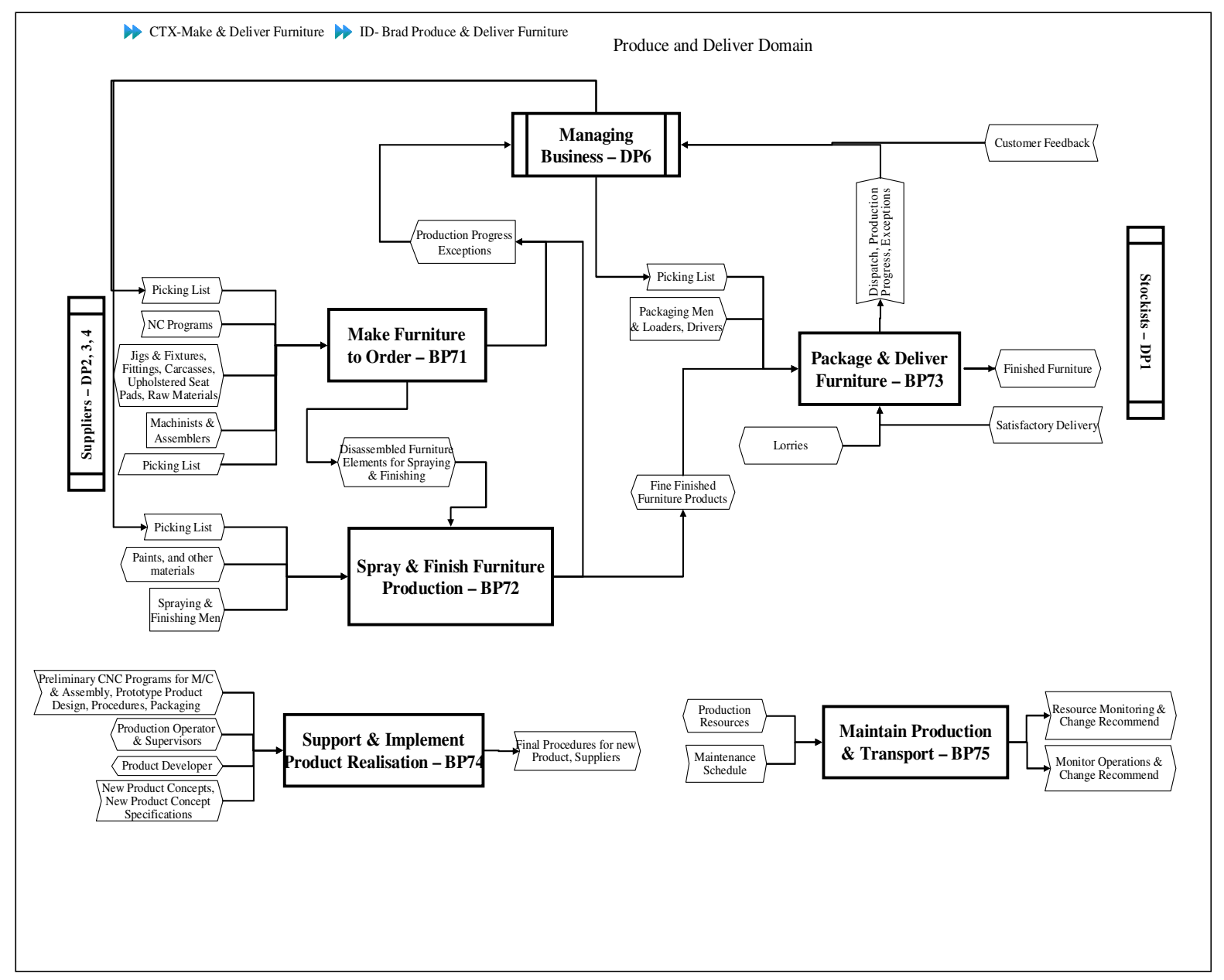

Figure 3: Sub-Interaction Diagram - DP7 decomposition 


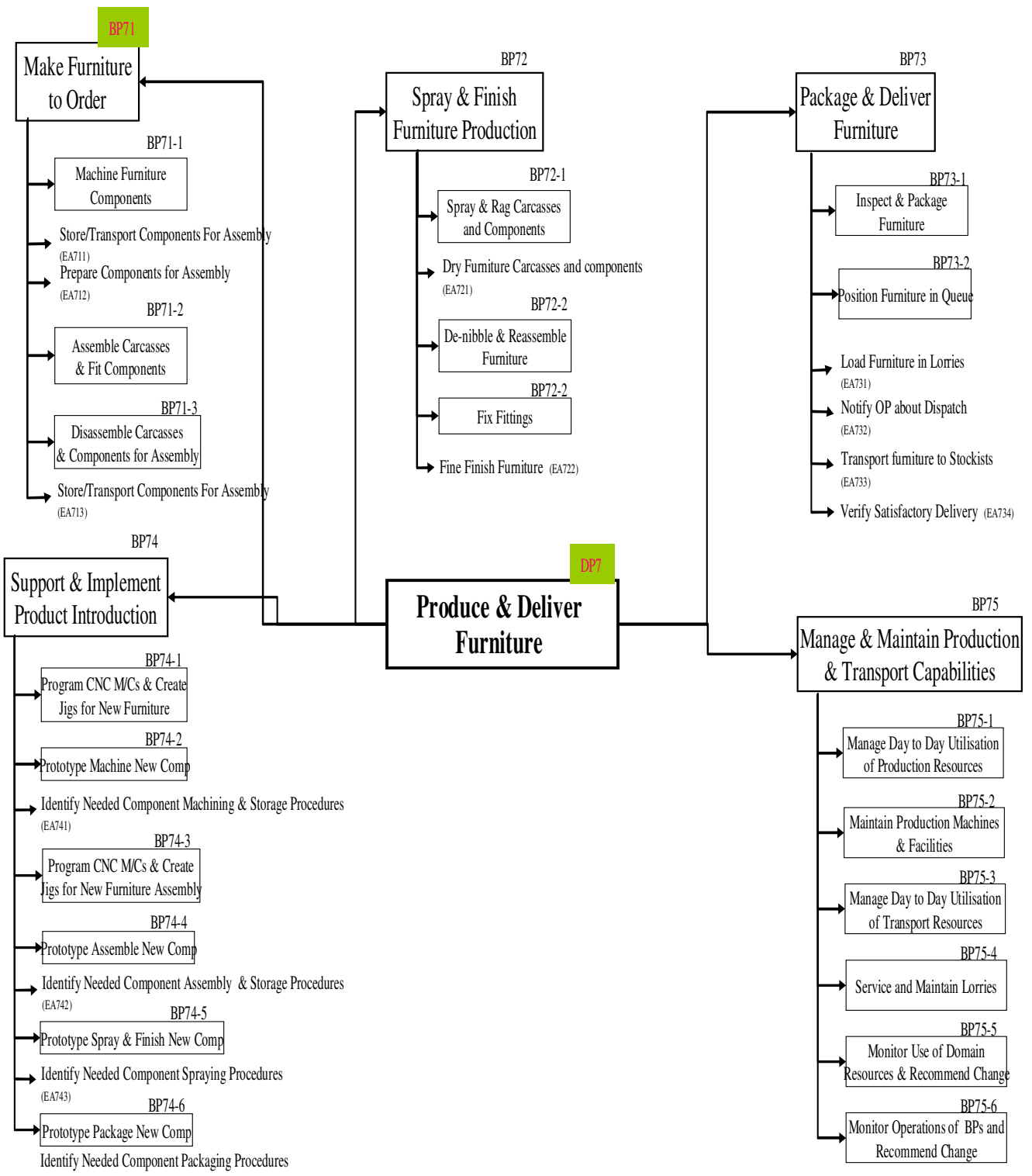

(EA74)

Figure 4 Structure diagram for process segments comprising the 'Produce and Deliver Furniture' DP7 
BP723

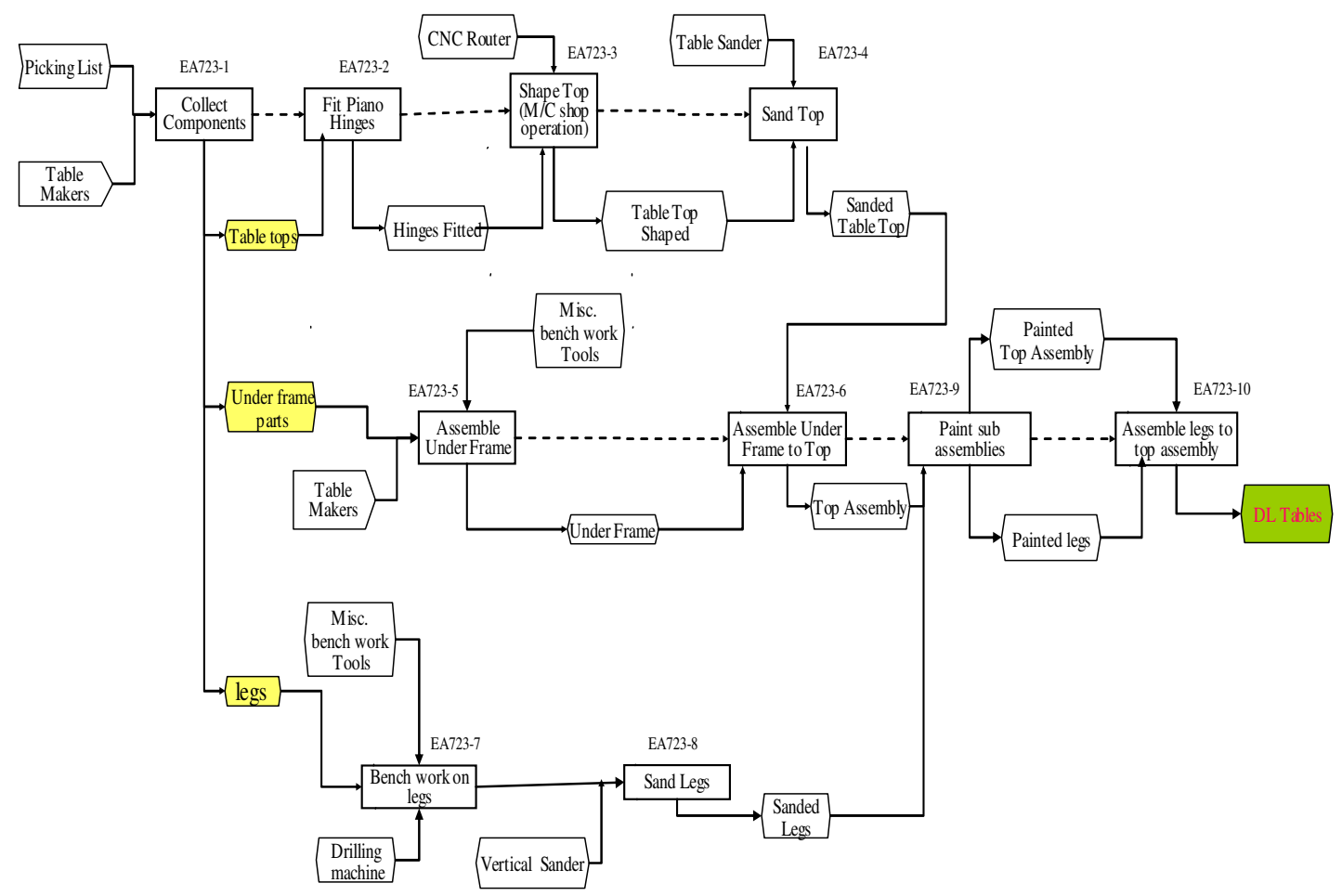

Figure 5 Activity diagram 

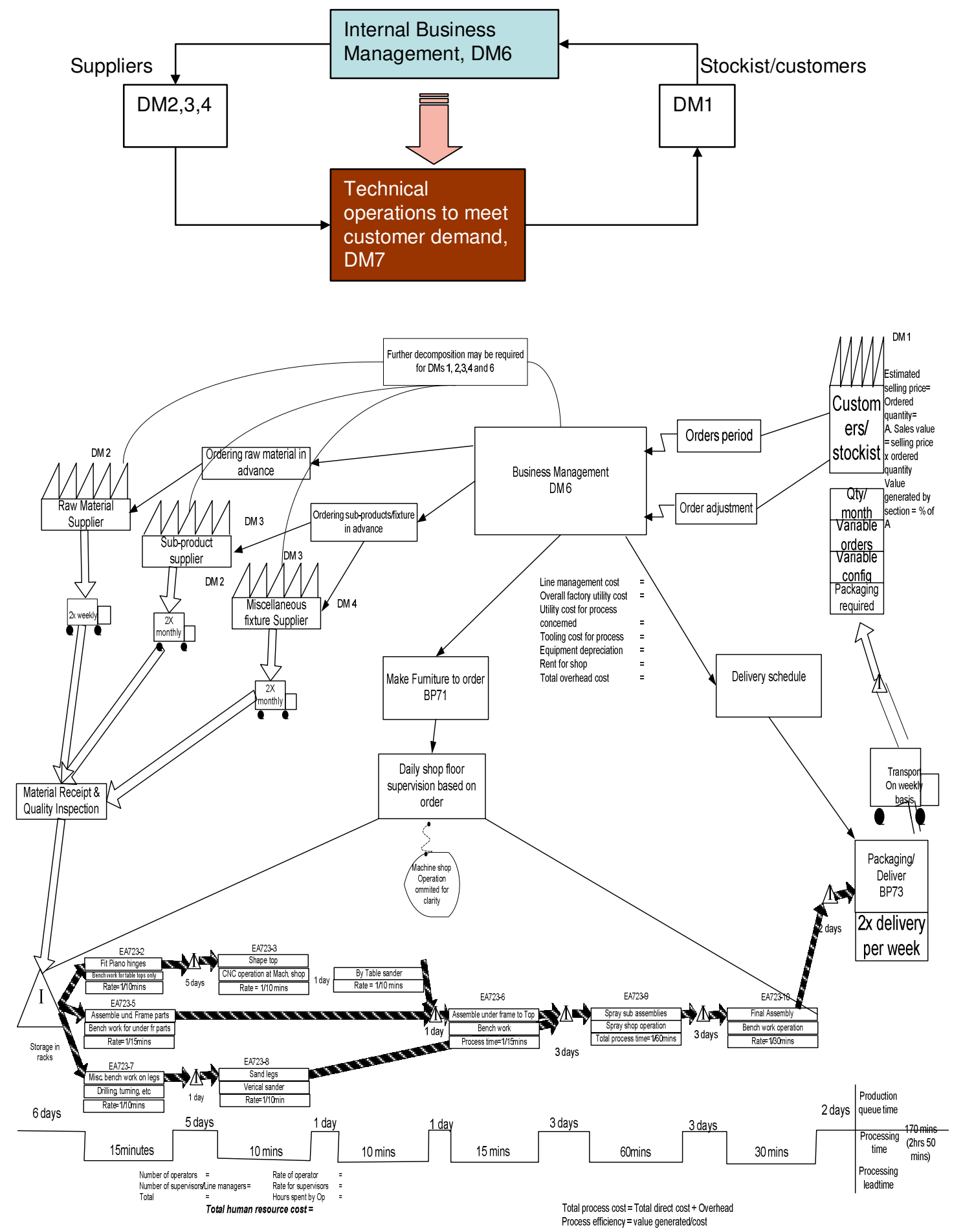

Figure 6 Current state map of assembly section 


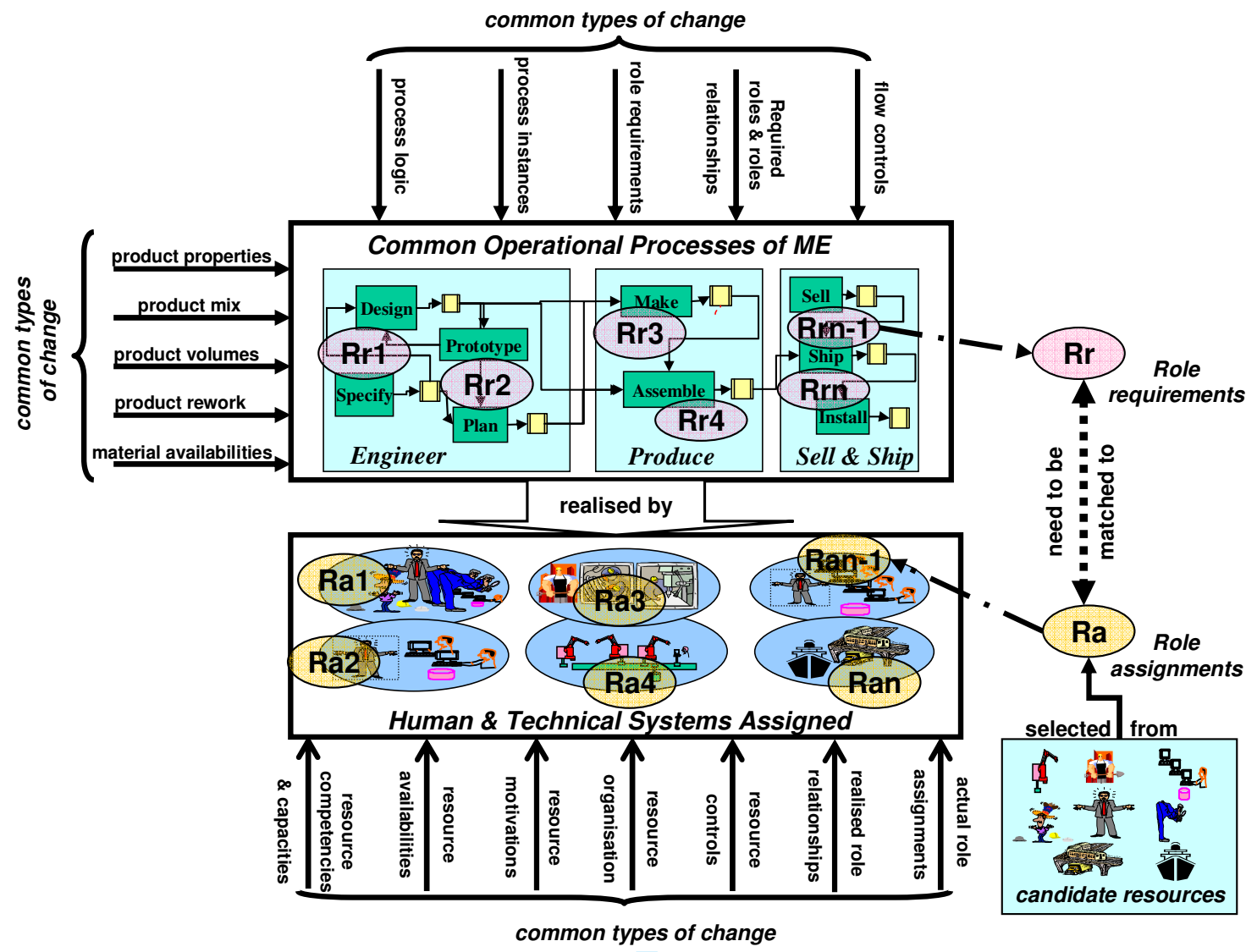

Figure 7 Types of changes on MEs(Weston, Rahimifard et al. 2007) 


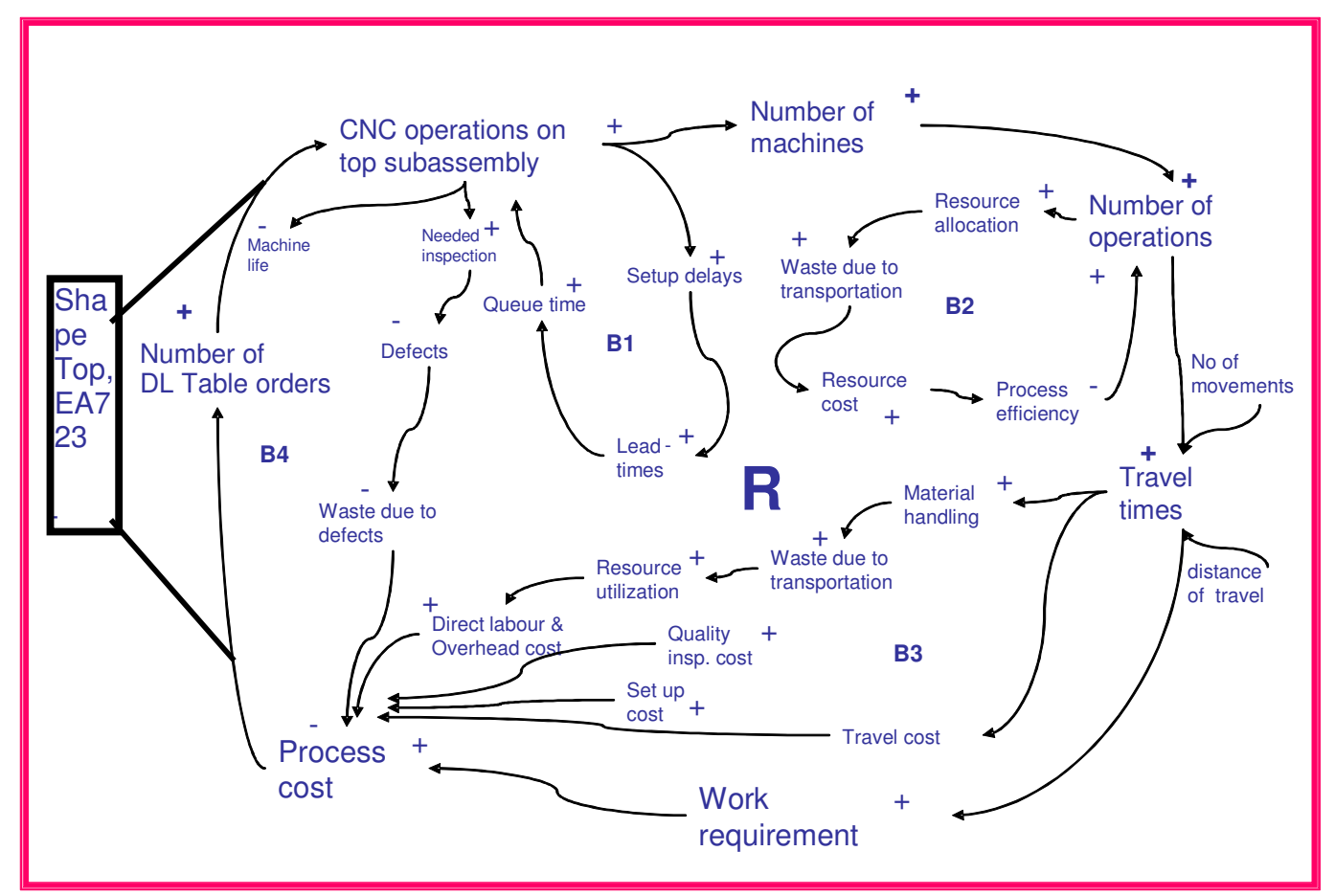

Figure 8: Influence loop 1

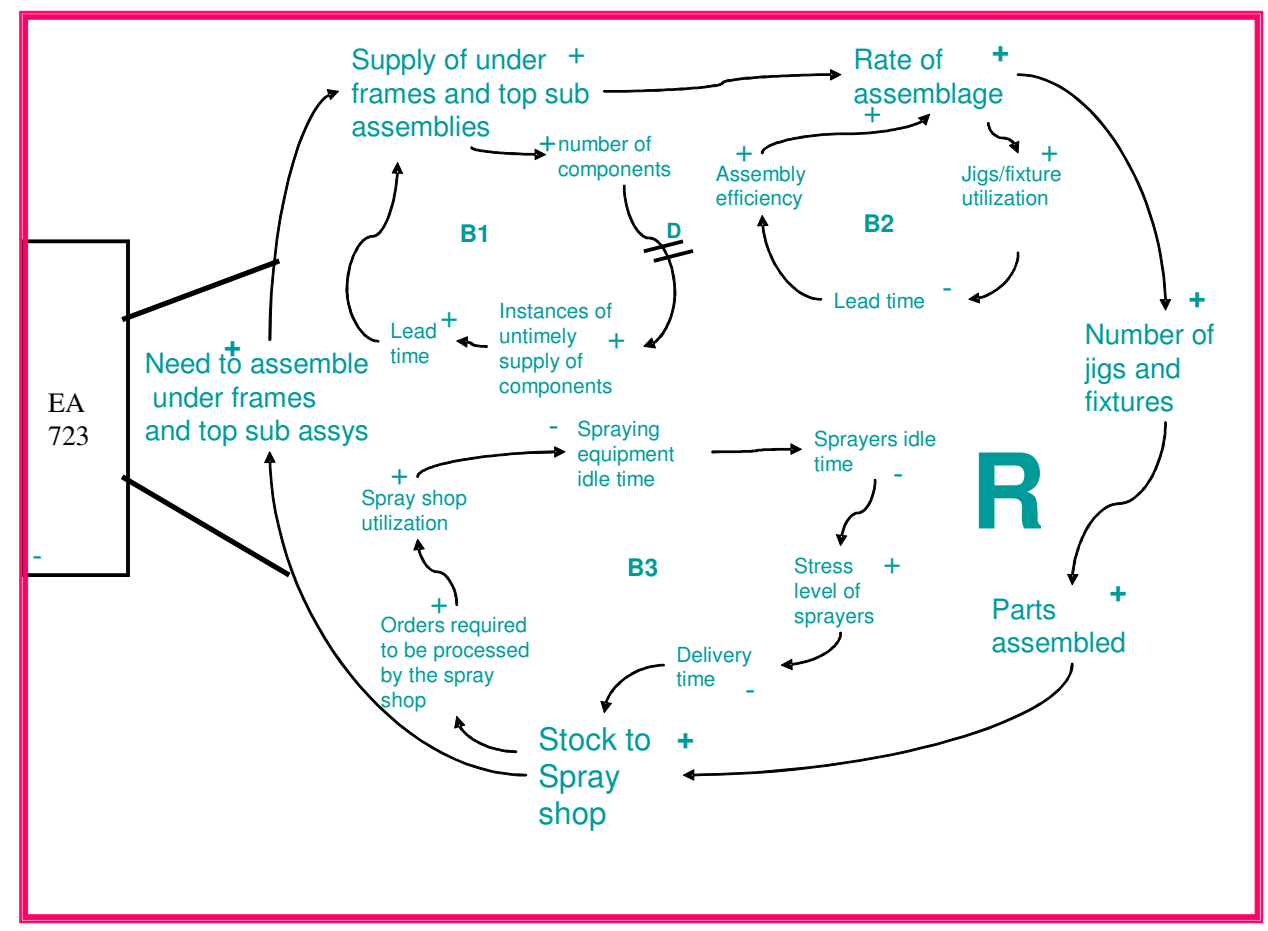

Figure 9 Influence loop 2 for decision making 


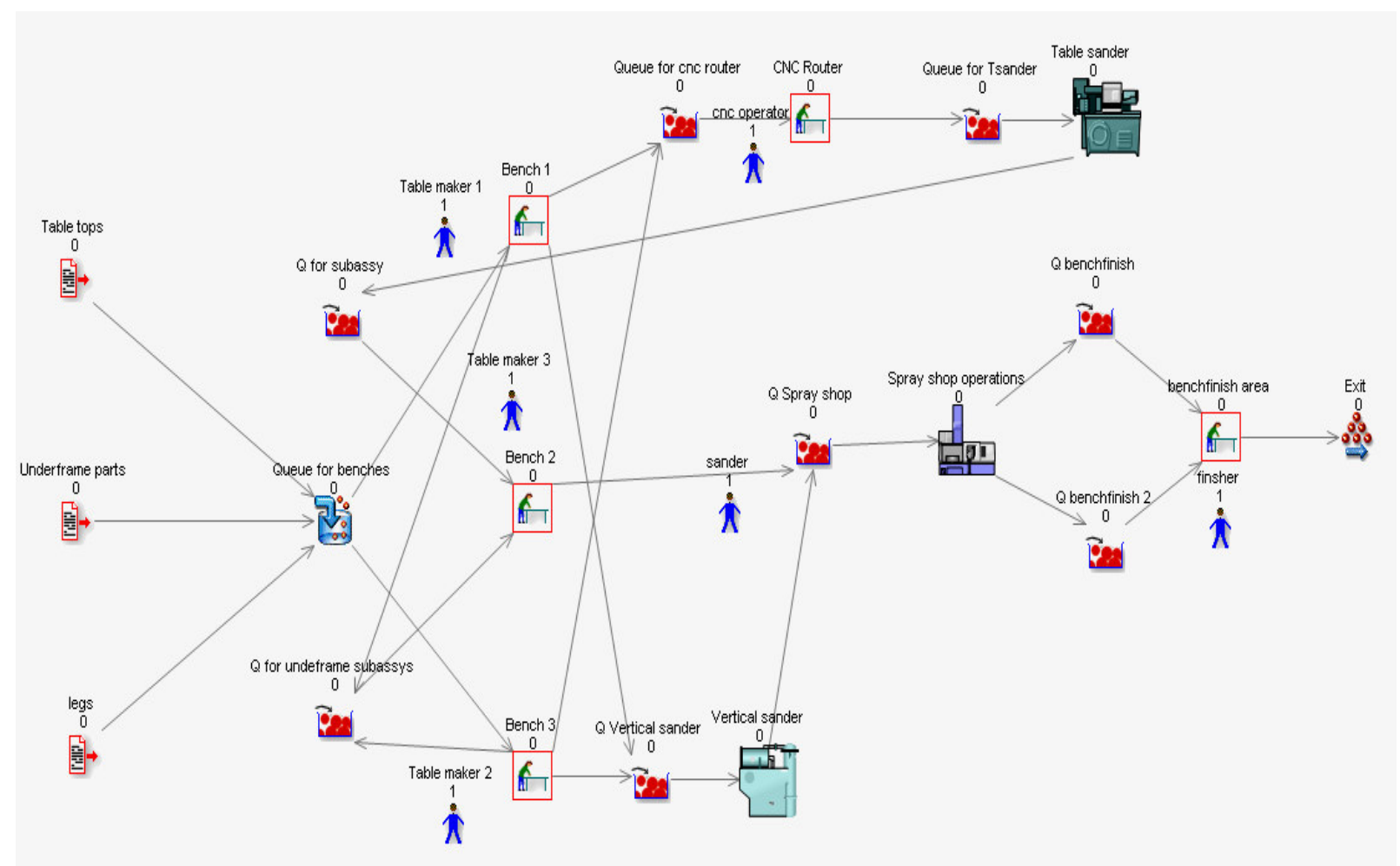

Figure 10 Snapshot of the Simul 8 model 